\title{
Even worms matter: cave habitat restoration for a planarian species increased environmental suitability but not abundance
}

\author{
Raoul Manenti, Benedetta Barzaghi, Giandatista Tonni \\ Gentile Francesco Ficetola and Andrea Melotto
}

\begin{abstract}
Invertebrates living in underground environments often have unusual and sometimes unique adaptations and occupy narrow ranges, but there is a lack of knowledge about most micro-endemic cave-dwelling invertebrate species. An illustrative case is that of the flatworm Dendrocoelum italicum, the first survey of which was performed 79 years after its description. The survey revealed that the underground stream supplying water to the pool from which the species was first described had been diverted into a pipe for human use, thus severely reducing the available habitat for the species. Here we describe the results of what we believe is the first habitat restoration action performed in a cave habitat for the conservation of a flatworm. The water-diverting structure was removed, with the involvement of local protected area administrators, citizens and volunteers from local organizations. The intervention resulted in the restoration of a large, stable pool inside the cave, thus creating an optimal habitat for this threatened planarian, with increased availability of prey and a stable population. This report of habitat restoration for a neglected invertebrate offers insights for the protection of other micro-endemic species.
\end{abstract}

Keywords Cave, Dendrocoelum italicum, flatworm, freshwater, hypogean, Italy, planarian, restoration, subterranean

\section{Introduction}

ubterranean environments such as caves, shallow sub$\checkmark$ terranean habitats and underground aquifers are among the most vulnerable habitats, often requiring conservation attention (Culver \& Pipan, 2009; Pipan et al., 2010). Increasingly, studies are emphasizing the importance of conservation approaches based on habitat restoration (Perring et al., 2015; Chazdon et al., 2017; Canedoli et al., 2018). Ecologically important areas such as ecotones,

Raoul Manenti (Corresponding author), Benedetta Barzaghi, Gentile Francesco Ficetola and Andrea Melotto Dipartimento di Scienze e Politiche Ambientali, Università degli Studi di Milano, Via Celoria, 26, Milano 20133, Italy. E-mail raoulmanenti@gmail.com @ orcid.org/0000-0001-6071-8194

Gianbattista Tonni Monumento Naturale Altopiano di Cariadeghe, Serle, Italy

Received 19 March 2018. Revision requested 13 April 2018.

Accepted 16 May 2018. First published online 18 December 2018. ponds and wetlands have been restored successfully (Bergmeier et al., 2010; Romano et al., 2010; Lü et al., 2012; Merenlender \& Matella, 2013) but there are not, to our knowledge, any documented cases of freshwater restoration involving cave habitats.

Subterranean environments generally exhibit environmental stability and are heterotrophic systems of key importance for the surrounding surface habitats (Culver \& Pipan, 2009; Barzaghi et al., 2017): they work as recharge sites for surface waters, control water flux and exchanges with the surface, and provide shelter for key organisms such as bats, which sustain a variety of ecosystem services, including pollination, seed dispersal and pest control (Souza Silva et al., 2015). Cave environments are sensitive to threats such as climate change and groundwater pollution, but are also affected by other local or regional factors such as quarrying (Di Maggio et al., 2012), irresponsible exploitation for tourism (Ivanova, 2017), and water harnessing and diversion (Achurra \& Rodriguez, 2008). All of these threats are likely to affect cave and subterranean ecosystems significantly, but they have been poorly studied.

Underground habitats are of special importance for biodiversity conservation because they often host a highly specialized fauna (Culver \& Pipan, 2009; Romero, 2009). Moreover, most organisms that live in caves are highly restricted geographically and low in abundance (Zagmajster et al., 2008; Delić et al., 2017). Predators, sunlight and environmental variations occurring on the surface may be important environmental conditions for a number of caveadapted organisms (Culver \& Pipan, 2009). Micro-endemic invertebrate species, both stygobionts (specialized aquatic cave-dwelling organisms) and troglobionts (specialized terrestrial cave-dwelling organisms), are in some cases known only from one or a few caves (Culver \& Pipan, 2014; Mammola \& Isaia, 2016; Wei et al., 2017).

However, endemic invertebrate species are rarely considered in conservation programmes (Cardoso et al., 2011; Noreika et al., 2015) despite their ecological importance. Cave-dwelling endemic invertebrates can play an important functional role in karst ecosystems, facilitating nutrient recycling and biomass exchange (Schneider et al., 2011). Among cave invertebrates, planarians are free-living flatworms generally characterized by zoophagous feeding behaviour, preying mainly on small living invertebrates and grazing on decaying organisms (Reynoldson \& Young, 
2000). Most planarian species are particularly sensitive to organic matter pollution and water quality (Horvat et al., 2005; Alonso \& Camargo, 2006; Manenti, 2010). Nearly 200 species, including marine and freshwater species, have been recorded in cave habitats (Romero, 2009). Most of the species described are blind and depigmented, thus showing a strong adaptation to cave life (Stocchino et al., 2013). Cave-dwelling planarians occur in subterranean habitats worldwide (Gourbault, 1972; Carpenter, 1982; Sluys et al., 2009), but most of the described species have extremely narrow ranges, in many cases being confined to a single cave (De Beauchamp, 1932). For most known cave-dwelling planarians no further study has been conducted beyond the description of the species. Generally, no additional information has been reported after collection of the specimens used for description, and even the information reported with the description is often secondhand. In many cases descriptions were performed by anatomists specialized in Platyhelminthes, who never entered the caves but received specimens from speleologists. Moreover, cavedwelling planarians are adapted to interstices in which they shelter, and even when cave pools or streams host abundant populations, planarians are not easily detected (Gourbault, 1972) and, consequently, it is difficult to assess their conservation status.

This situation is exemplified by the flatworm Dendrocoelum italicum (Benazzi, 1982), which was described in 1937 in the Bus del Budrio cave in the Italian Prealps (Vialli, 1937). The description of the species includes information about the habitat where it was found: a large subterranean pool below a small waterfall. In 2016 we discovered that the species was threatened by a structure that was diverting water from the waterfall into a pipe. Water was no longer reaching the pool, which had completely dried up, and D. italicum was confined to a short rivulet and a couple of tiny secondary pools.

We therefore began what we believe is the first habitat restoration action performed in a cave habitat (Plate 1 ) for the conservation of a flatworm species, aiming to investigate whether the restoration technique applied was appropriate. In particular, we predicted that (1) the abundance of this cave-dwelling planarian would increase shortly after the restoration, and (2) habitat restoration would increase the occurrence of the invertebrate prey of $D$. italicum.

\section{Study site}

The Bus del Budrio cave is in the Italian Prealps (Fig. 1) in the regional protected area of Cariadeghe, in northern Italy. The cave consists of an elongated chamber ( $43 \mathrm{~m}$ long, $6.5 \mathrm{~m}$ high), which opens at the cave entrance and is connected to an elevated narrow and sinuous corridor located on the north-western side. A small stream runs along the corridor

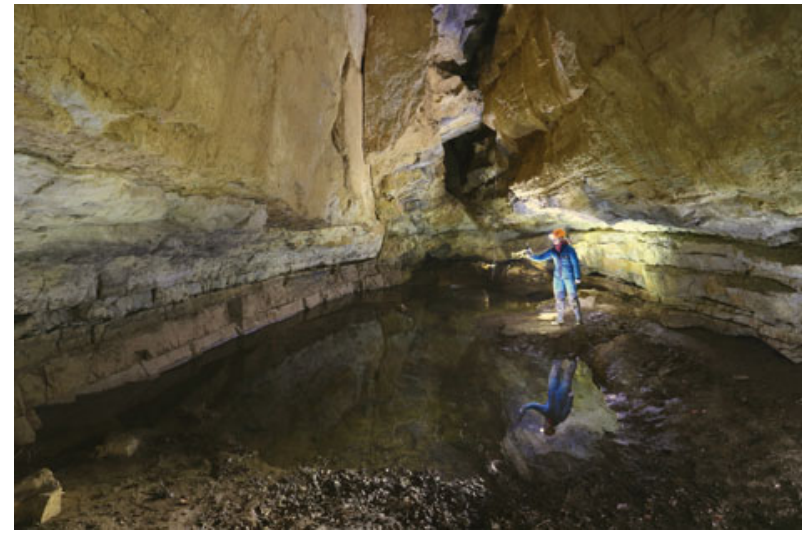

Plate 1 The restored pool in the Bus del Budrio cave (Fig. 1) in February 2018. Photograph by Luana Aimar.

and after $20 \mathrm{~m}$ forms a waterfall. In 1937, when D. italicum was described, a small waterfall filled a large pool, with a surface area of at least $5 \times 5 \mathrm{~m}$ (Fig. 1). During the $1980 \mathrm{os}$ the water was diverted to a farm close to the cave (GT, pers. obs.). This left only a small trickle flowing down to form a bipartite rivulet $6 \mathrm{~m}$ long and $50 \mathrm{~cm}$ wide (Fig. 2a). As a result of this environmental alteration, the pool dried up permanently.

\section{Methods}

\section{Habitat restoration}

In April 2016 we observed that the planarian D. italicum still occurred in the small rivulet. The rivulet appeared to be suboptimal, having a consistent flow and apparently poor prey occurrence, whereas the typical requirements of Dendrocoelum planarians are for standing waters (Gourbault, 1972) with relatively abundant invertebrate prey (Reynoldson \& Young, 2000).

Firstly, we assessed the status and distribution of the species at the site (see below). Secondly, we informed the administrators of the protected area about the critical condition of the species and the need for immediate conservation action. Thirdly, we helped the protected area administrators to raise awareness about the species amongst citizens that use the reservoir for recreational activities and to obtain the agreement of the farmer responsible for diverting the water. Fourthly, we involved a local caving group, who volunteered to remove the structure diverting the water flow. On 3 December 2016 we collected all the planarians occurring in the rivulet, stored them in plastic tanks inside the cave, and removed both the duct feeding the small rivulet and the barrier that conveyed the water into it above the waterfall. Removal required 3 hours of work by five people. All artificial material was removed from the cave. When the water started to flow along its natural course we used shovels to compact the substrate under the waterfall, to 


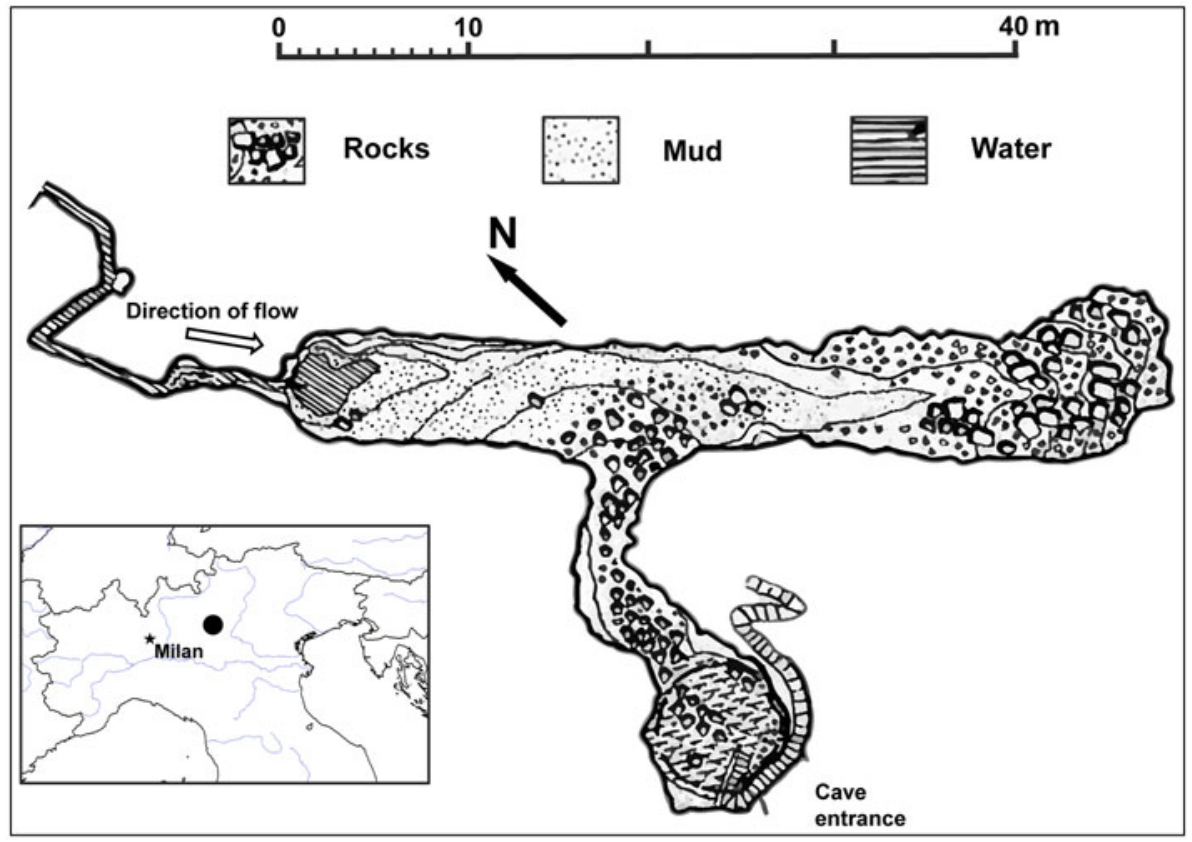

FIg. 1 Plan of the Bus del Budrio cave redrawn from the original survey performed by Allegretti and Trevisani of the Gruppo Grotte Brescia (19 September 1926) and subsequently published by Vailati (1979). The black circle on the inset indicates the location of the cave in northern Italy.
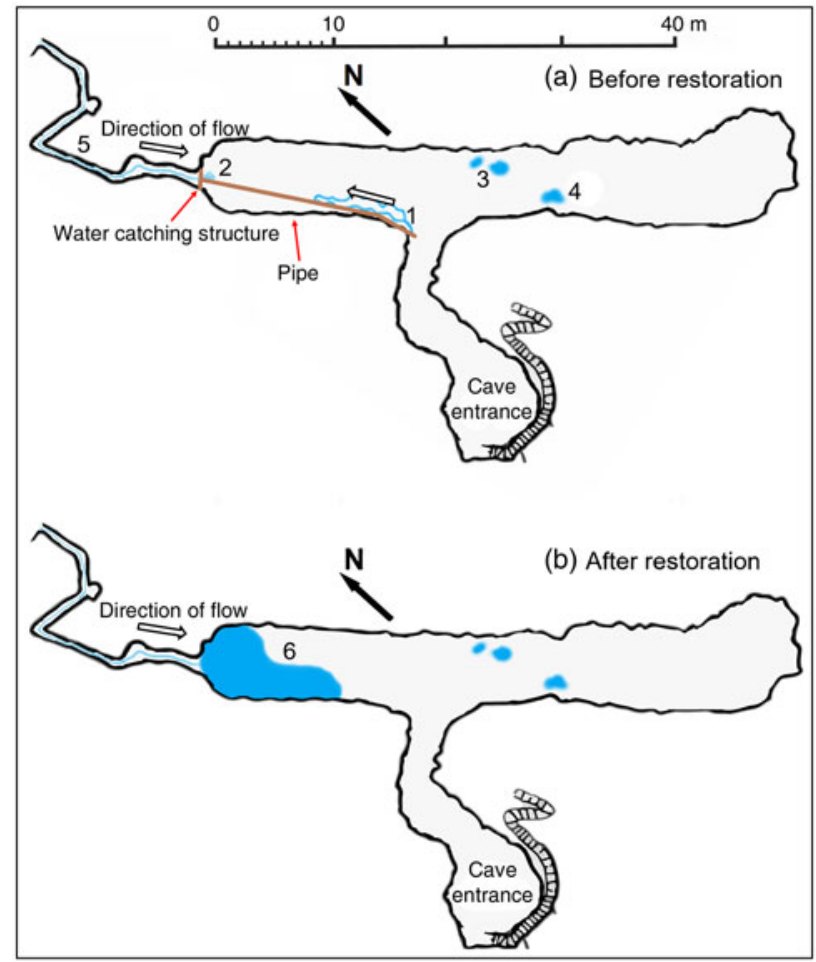

FIG. 2 The extent of the freshwater habitats of the Bus del Budrio cave (Fig. 1), (a) before and (b) after habitat restoration. 1 , a small rivulet formed by an artificial water-catching structure installed in the 1980s; 2-4, pools resulting from drips; 5, small subterranean stream; 6 , a pool fed by the subterranean stream after removal of the water-catching structure.

avoid water infiltration and to facilitate the filling of the former pool (Fig. 2b). In the following months of December and January the water column was highly turbid because of sediment suspension.

\section{Dendrocoelum italicum assessment and relocation}

We performed 18 surveys during February 2016-January 2018 to assess the status of D. italicum (Table 1): six before the habitat restoration, three during the restoration activities, and nine after restoration. At each survey the same (one or two) observers used the 30-minute visual encounter survey technique to count the number of planarians in all the freshwater habitats of the cave (Gourbault, 1972). After the intervention, the restored large pool replaced the small rivulet and a pool fed by drips. Surveys covered exactly the same area before and after the restoration. When the original pool started to fill from the fully restored waterfall, on 4 December 2016, we released all the collected planarians into it. In February 2016 and February 2018 we assessed the density of the potential invertebrate prey by performing 10 consecutive samplings with a thin-mesh dip net. The invertebrate surveys were repeated at three locations, chosen randomly.

\section{Data analysis}

We used random-effect Poisson generalized linear mixed models to assess the relationships between the relative abundance of $D$. italicum and habitat restoration activities (Barker et al., 2018). Poisson generalized linear mixed models produce reliable estimates of the relationships between the relative abundance of species and habitat variation. Simulations performed by Barker et al. (2018) showed that the estimates obtained through Poisson generalized linear mixed models are consistent with those obtained using alternative approaches ( $\mathrm{N}$-mixture models, double Poisson models), and are particularly appropriate for species for 
TABLE 1 Details of surveys of the planarian Dendrocoelum italicum in Bus del Budrio cave in the regional protected Aarea of Cariadeghe, northern Italy (Fig. 1), before the intervention to remove a structure diverting the water flow, during the stabilization period and after the intervention.

\begin{tabular}{|c|c|c|c|c|}
\hline Date & $\begin{array}{l}\text { Time of } \\
\text { survey }\end{array}$ & $\begin{array}{l}\text { No. of D. italicum } \\
\text { observed }\end{array}$ & $\begin{array}{l}\text { Air } \\
\text { temperature }\left({ }^{\circ} \mathrm{C}\right)\end{array}$ & $\begin{array}{l}\text { No. of } \\
\text { observers }\end{array}$ \\
\hline \multicolumn{5}{|c|}{ Before the intervention } \\
\hline 4 Feb. 2016 & Day & 49 & & 1 \\
\hline 22 Apr. 2016 & Day & 69 & & 2 \\
\hline 27 July 2016 & Night & 109 & 10.7 & 1 \\
\hline 15 Nov. 2016 & Day & 41 & 10.6 & 2 \\
\hline 18 Nov. 2016 & Day & 8 & & 2 \\
\hline 27 Nov. 2016 & Day & 43 & & 2 \\
\hline \multicolumn{5}{|c|}{ Stabilization period (turbid water) } \\
\hline 3 Dec. 2016 & (planarians removed) & 73 & 5.2 & 1 \\
\hline 4 Dec. 2016 & Day $^{1}$ & 6 & 5.6 & 2 \\
\hline 25 Jan. 2017 & Day & 7 & -3.8 & 2 \\
\hline \multicolumn{5}{|c|}{ After the intervention } \\
\hline 19 Mar. 2017 & Day & 52 & 9.4 & 2 \\
\hline 22 Mar. 2017 & Night & 109 & & 1 \\
\hline 30 Mar. 2017 & Day & 26 & 6.1 & 2 \\
\hline 30 Mar. 2017 & Night & 58 & 6.2 & 2 \\
\hline 31 Mar. 2017 & Day & 43 & 6.9 & 2 \\
\hline 31 Mar. 2017 & Night & 91 & 6.2 & 2 \\
\hline 1 Apr. 2017 & Day & 31 & 6.6 & 2 \\
\hline 24 Jan. 2018 & Day & 65 & 0.5 & 2 \\
\hline 24 Jan. 2018 & Night & 81 & 0.5 & 2 \\
\hline
\end{tabular}

${ }^{1}$ After all collected planarians had been returned to the water.

TABLE 2 Density of invertebrate prey of D. italicum in Bus del Budrio cave (Fig. 1) before (February 2016) and after (February 2018) habitat restoration.

\begin{tabular}{lcc}
\hline & \multicolumn{2}{l}{ Density $\pm \mathrm{SE}$ (individuals $/ \mathrm{m}^{2}$ ) } \\
\cline { 2 - 3 } Taxon & $\begin{array}{l}\text { Before } \\
\text { restoration }\end{array}$ & $\begin{array}{l}\text { After } \\
\text { restoration }\end{array}$ \\
\hline $\begin{array}{l}\text { Pisidium personatum } \\
\quad \text { (Mollusca) }\end{array}$ & $32.7 \pm 6.48$ & $88.6 \pm 0.88$ \\
Haplotaxidae & 0 & $11.25 \pm 0.74$ \\
Niphargus sp. (Crustacea) & $0.7 \pm 0.35$ & $0.82 \pm 0.47$ \\
\hline
\end{tabular}

which detection probability of individuals is low. The dependent variable was the number of planarians observed in the whole cave in each survey. We included the time of observation (day/night) as a covariate. The period of observation (before, during stabilization or after the intervention) was included as a fixed factor, and the date of the survey was included as a random factor, as some surveys were conducted at different times on the same date. We distinguished between the after intervention and stabilization periods because after the remediation action the water was highly turbid, which probably affected planarian detectability. We assessed the significance of variables using a likelihood ratio test. The model did not exhibit overdispersion (residual deviance $=9.8$; residual degrees of freedom $=11$ ). A Tukey post-hoc test was used to determine the significance of differences in abundance in the intervention periods (before, during stabilization, and after intervention). A t test was used to assess differences between the density of potential invertebrate prey before and after the intervention. Analyses were performed in $R$ v.3.3.2 ( $\mathrm{R}$ Development Core Team, 2016) using the package lme4.

\section{Results}

The restoration was successful in achieving stable hydrological conditions in the pool inside the cave $\left(21 \mathrm{~m}^{2}\right.$ surface area, $15 \mathrm{~cm}$ mean depth). At the time of restoration, 73 planarians ( 58 adults, 15 juveniles) were removed from the rivulet and released the next day in the restored pool, when its conditions became stable. The number of planarians detected per survey was highly variable among surveys: 8-109 individuals before the restoration, and 31-109 individuals after the restoration (Table 1). Comparing winter surveys, the density and variability of available prey was significantly higher after the restoration (Table 2). In particular, after the restoration we detected significantly more bivalves Pisidium personatum $(t=8.55, \mathrm{P}=0.01)$, and annelids of the family Haplotaxidae that were not present before $(t=15, \mathrm{P}<0.01)$. A small, non-significant increase (from 0.7 to 0.8 individuals $/ \mathrm{m}^{2}$ ) was detected in the number of crustaceans of the genus Niphargus.

The number of planarians was higher during night surveys (Poisson generalized linear mixed model: 
$\left.\chi^{2}=28.17, \mathrm{df}=1, \mathrm{P}<0.0001\right)$. During the period after the intervention we did not detect significant differences in abundance (Tukey's post-hoc test: $\mathrm{P}=0.85$ ).

\section{Discussion}

As far as we are aware, this is the first case of restoration of a cave habitat hosting a planarian species. The intervention helped to restore the original habitat conditions in the type locality of the endemic planarian D. italicum. As we detected no significant difference in the number of planarians before and after the restoration, the population at least remained stable. However, environmental conditions in the cave changed considerably: a large shallow lentic habitat oxygenated by the waterfall became available and the density and diversity of suitable invertebrate prey increased.

The few available studies suggest that cave-dwelling planarians prefer shallow standing pools (Ginet \& Puglisi, 1964; Gourbault, 1972). The epigean species of the genus Dendrocoelum are also normally reported from standing waters (Reynoldson \& Young, 2000), and therefore the restored conditions probably provide more suitable environmental conditions for $D$. italicum than those prevailing before the restoration. Restoration of the water flow rapidly recreated a large pool in the western part of the cave. The restored environmental features are also suitable for species that need oxygenated waters, such as Niphargus sp., and for species of standing water, such as the molluscs and annelids observed. The increased availability of potential prey following habitat restoration has augmented the amount and quality of the trophic resources available to the planarians.

The number of planarians was significantly lower in the 2 months immediately after the restoration. In this period water turbidity was high and probably limited detection. The similarity in planarian density before and after restoration suggests that more time is needed to assess the effects of habitat restoration on population dynamics. Breeding cycles are generally long in Dendrocoelum species, which are considered to be semelparous (Young \& Reynoldson, 1965), and cycles may be even more prolonged in cavedwelling species of the genus (Gourbault, 1972).

Planarians were more active at night. Although most freshwater planarians are known to be photonegative (De Beauchamp, 1932; Reynoldson \& Young, 2000), their diel rhythms have rarely been quantified. Two non-exclusive hypotheses may explain the differential activity of $D$. italicum. Firstly, although they do not have eyes, $D$. italicum individuals may be able to perceive some light from the cave entrance. Secondly, the species may have retained circadian rhythms from a surface ancestor.

To our knowledge, the only other case of a worm that involved zoological studies, citizens' awareness and conservation actions is that of Macrocotyla glandulosa (Romero,
2009). This species is also the only cave-dwelling planarian that is monitored regularly for conservation purposes (Wicks et al., 2010). Our study demonstrates that it is possible to establish a successful conservation programme for a neglected invertebrate species. Generally, little attention is given to worms and other invertebrate species that have limited appeal to the public or protected area administrators (Cardoso et al., 2011). In our project, however, the involvement of administrators of the regional protected area of Cariadeghe and local citizens was central to its success. The citizens demonstrated an interest in the uniqueness of this planarian species and, together with the farmer responsible for previously diverting the water, approved the decision of the protected area administrators to restore the cave habitat. Most cave invertebrates have narrow ranges, and although they attract the interest of taxonomists, they are otherwise little studied (Culver \& Pipan, 2014). This situation often results in large gaps in knowledge following species' description, especially for species described long ago (Leroux \& Schmiegelow, 2007). It is likely that numerous micro-endemic invertebrate species are in a similar situation to D. italicum, and our results provide insights for the conservation of micro-endemic invertebrate species and cavedwelling flatworms.

In particular, our study provides two messages: the feasibility of including neglected invertebrate taxa in restoration programmes that lead to general habitat improvement, and the role that endemism can play in fostering people's empathy towards invertebrates. Conservation management of cave invertebrate species may be encouraged by drawing attention to the unique role of such species.

Acknowledgements The research was financed by The Mohamed bin Zayed Species Conservation Fund, project no. 162514520. We thank Andrea Poli and the Gruppo Grotte Brescia for their speleological intervention and the material provided, and Giorgio Scarì and Roberta Pennati for useful comments and support.

Author contributions Concept, data collection and writing: RM; data collection and habitat restoration: BB; provision of logistics, materials and site access, and organization of habitat restoration: GT; data analysis and writing: GFF; data collection, analysis and writing: AM.

\section{Conflicts of interest None.}

Ethical standards The research and intervention were approved by the Monumento Naturale Regionale Altopiano di Cariadeghe.

\section{References}

Achurra, A. \& Rodriguez, P. (2008) Biodiversity of groundwater oligochaetes from a karst unit in northern Iberian Peninsula: ranking subterranean sites for conservation management. Hydrobiologia, 605, 159-171.

Alonso, A. \& Camargo, J.A. (2006) Toxicity of nitrite to three species of freshwater invertebrates. Environmental Toxicology, 21, 90-94. 
Barker, R.J., Schofield, M.R., Link, W.A. \& Sauer, J.R. (2018) On the reliability of N-mixture models for count data. Biometrics, 74 , 369-377.

Barzaghi, B., Ficetola, G.F., Pennati, R. \& Manenti, R. (2017) Biphasic predators provide biomass subsidies in small freshwater habitats: a case study of spring and cave pools. Freshwater Biology, 62, 1637-1644.

Benazzi, M. (1982) Tricladi cavernicoli italiani. Lavori Società Italiana di Biogeografia, 7, 7-14.

Bergmeier, E., Petermann, J. \& Schröder, E. (2010) Geobotanical survey of wood-pasture habitats in Europe: diversity, threats and conservation. Biodiversity and Conservation, 19, 2995-3014.

Canedoli, C., Crocco, F., Comolli, R. \& Padoa-Schioppa, E. (2018) Landscape fragmentation and urban sprawl in the urban region of Milan. Landscape Research, 43, 632-651.

Cardoso, P., Erwin, T.L., Borges, P.A.V. \& New, T.R. (2011) The seven impediments in invertebrate conservation and how to overcome them. Biological Conservation, 144, 2647-2655.

CARPENTER, J.H. (1982) Observations on the biology of cave planarians of the United States. International Journal of Speleology, 12, 9-26.

Chazdon, R.L., Brancalion, P.H.S., Lamb, D., Laestadius, L., Calmon, M. \& Kumar, C. (2017) A policy-driven knowledge agenda for global forest and landscape restoration. Conservation Letters, 10, 125-132.

Culver, D.C. \& Pipan, T. (2009) The Biology of Caves and other Subterranean Habitats. Oxford University Press, New York, USA.

Culver, D.C. \& Pipan, T. (2014) Shallow Subterranean Habitats. Oxford University Press, Oxford, UK.

De Beauchamp, P. (1932) Biospeleologica. Turbellariés, Hirudinées, Branchiobdellidés (Deuxième série). Archives de Zoologie Expérimentale et Générale: histoire naturelle, morphologie, histologie, évolution des animaux, 73, 113-380.

Delić, T., Trontelj, P., Rendoš, M. \& Fišer, C. (2017) The importance of naming cryptic species and the conservation of endemic subterranean amphipods. Scientific Reports, 7, 3391.

Di Maggio, C., Madonia, G., Parise, M. \& Vattano, M. (2012) Karst of Sicily and its conservation. Journal of Cave and Karst Studies, 74, 157-172.

Ginet, R. \& Puglisi, R. (1964) Écologie de Fonticola notadena de Beauchamp (Turbellarié, Triclade) dans la grotte de La Balme (Isère, France); survie en période de sécheresse. International Journal of Speleology, 1, 203-216.

Gourbault, N. (1972) Recherches sur les Triclades Paludicoles hypogés. Mémoires du Muséum National d'Histoire Naturelle. Serie A, 73, 1-249.

Horvat, T., Kalafatić, M., Kopjar, N. \& Kovačević, G. (2005) Toxicity testing of herbicide norflurazon on an aquatic bioindicator species - the planarian Polycelis felina (Daly.). Aquatic Toxicology, $73,342-352$.

IvanOVA, S. (2017) Influence of tourists on the summer bat colonies in the Devetashka Cave, Bulgaria. Acta Zoologica Bulgarica, 8, 211-216.

Leroux, S.J. \& Schmiegelow, F.K.A. (2007) Biodiversity concordance and the importance of endemism. Conservation Biology, 21, 266-268.

LÜ, Y., Fu, B., Feng, X., Zeng, Y., LiU, Y., Chang, R. et al. (2012) Policy-driven large scale ecological restoration: quantifying ecosystem services changes in the Loess Plateau of China. PLOS ONE, 7, e31782.

Mammola, S. \& Isaia, M. (2016) The ecological niche of a specialized subterranean spider. Invertebrate Biology, 135, 20-30.

Manenti, R. (2010) The role of watercourse features and of landscape structure in the distribution of Triclads inhabiting head waters: the example of Polycelis felina. Revue d'Écologie - la Terre et la Vie, 65, $279-285$.

Merenlender, A.M. \& Matella, M.K. (2013) Maintaining and restoring hydrologic habitat connectivity in Mediterranean streams: an integrated modeling framework. Hydrobiologia, 719, 509-525.

Noreika, N., Kotiaho, J.S., Penttinen, J., Punttila, P., Vuori, A., PaJUnen, T. et al. (2015) Rapid recovery of invertebrate communities after ecological restoration of boreal mires. Restoration Ecology, 23, 566-579.

Perring, M.P., Standish, R.J., Price, J.N., Craig, M.D., Erickson, T.E., Ruthrof, K.X. et al. (2015) Advances in restoration ecology: rising to the challenges of the coming decades. Ecosphere, 6, $1-25$.

Pipan, T., Holt, N. \& Culver, D.C. (2010) How to protect a diverse, poorly known, inaccessible fauna: identification and protection of source and sink habitats in the epikarst. Aquatic Conservation, 20, $748-755$.

R Development Core Team (2016) R: A Language and Environment for Statistical Computing. R Foundation for Statistical Computing, Vienna, Austria.

Reynoldson, J.D. \& Young, J.O. (2000) A Key to the Freshwater Triclads of Britain and Ireland with Notes on their Ecology. Freshwater Biological Association, Ambleside, UK.

Romano, A., Ventre, N., De Riso, L., Pignataro, C. \& Spilinga, C. (2010) Amphibians of the "Cilento e Vallo di Diano" National Park (Campania, Southern Italy): updated check list, distribution and conservation notes. Acta Herpetologica, 5, 233-244.

Romero, A. (2009) Cave Biology. Cambridge University Press, New York, USA.

Schneider, K., Christman, M.C. \& Fagan, W.F. (2011) The influence of resource subsidies on cave invertebrates: results from an ecosystem-level manipulation experiment. Ecology, 92, 765-776.

Sluys, R., Kawakatsu, M., Riutort, M. \& Baguña, J. (2009) A new higher classification of planarian flatworms (Platyhelminthes, Tricladida). Journal of Natural History, 43, 1763-1777.

Souza Silva, M., Martins, R.P. \& Ferreira, R.L. (2015) Cave conservation priority index to adopt a rapid protection strategy: a case study in Brazilian Atlantic rain forest. Environmental Management, 55, 279-295.

Stocchino, G.A., Sluys, R., Marcia, P. \& Manconi, R. (2013) Subterranean aquatic planarians of Sardinia, with a discussion on the penial flagellum and the bursal canal sphincter in the genus Dendrocoelum (Platyhelminthes, Tricladida, Dendrocoelidae). Journal of Cave and Karst Studies, 75, 93-112.

Vailati, D. (1979) Nota preliminare sulla fauna della grotta Omber en banda al Büs del Zel (247 Lo-BS). Natura Bresciana, 15, 60-68.

Vialli, M. (1937) Una nuova specie di Dendrocoelum delle grotte bresciane. Italian Journal of Zoology, 8, 179-187.

Wei, G., Chen, J. \& Tian, M. (2017) A review of the aphaenopsian ground beetle genus Uenotrechus Deuve et Tian, 1999 (Coleoptera: Carabidae: Trechinae). Zootaxa, 4282, 361-373.

Wicks, C., Noltie, D.B., Peterson, E.W. \& Dogwiler, T. (2010) Disturbances in the habitat of Macrocotyla glandulosa (Kenk). Ecohydrology, 3, 116-125.

Young, J.O. \& Reynoldson, T.B. (1965) A quantitative study of the population biology of Dendrocoelum lacteum (Müller). Oikos, 15, 237-264.

Zagmajster, M., Culver, D.C. \& Sket, B. (2008) Species richness patterns of obligate subterranean beetles (Insecta: Coleoptera) in a global biodiversity hotspot - effect of scale and sampling intensity. Diversity and Distributions, 14, 95-105. 